\title{
Wood-Reinforced Polyphthalamide Resins: MultiFunctional Composite Coating for Metal Substrates
}

\author{
M. Barletta, ${ }^{1}$ G. Rubino, ${ }^{2}$ V. Tagliaferri, ${ }^{1}$ F. Trovalusci, ${ }^{3}$ and S. Vesco ${ }^{1}$ \\ ${ }^{1}$ Dipartimento di Ingegneria dell'Impresa, Università degli Studi di Roma Tor Vergata, Via del Politecnico, 1-00133 Roma, Italy \\ ${ }^{2}$ Dipartimento di Economia e Impresa, Università degli Studi della Tuscia, Via del Paradiso, 47-01100 Viterbo, Italy \\ ${ }^{3}$ Università Niccolò Cusano, Via Don Carlo Gnocchi, 3-00166-Roma, Italy \\ Correspondence should be addressed to M. Barletta; barletta@ing.uniroma2.it
}

Received 25 February 2014; Accepted 30 June 2014; Published 20 August 2014

Academic Editor: Jose Ramon Leiza

Copyright (C) 2014 M. Barletta et al. This is an open access article distributed under the Creative Commons Attribution License, which permits unrestricted use, distribution, and reproduction in any medium, provided the original work is properly cited.

\begin{abstract}
Protective layers were deposited on aluminum substrates by dipping them inside a fluidized bed (FB) of wood and polyphthalamide powders. The experimental investigation looked into the influence of the main process parameters (number and composition of superimposed layers, heating temperature, and dipping time) on the visual appearance, scratch adhesion, wear resistance, and thermal insulation of the resulting coatings. Micromechanical and tribological responses of the coatings were significantly improved by the effect of the wooden particles dispersed inside the polyphthalamide binder. An improvement of the thermal insulation was also achieved whatever the setting of the process parameters. Further, the coatings displayed good adhesion to the substrate and wear endurance.
\end{abstract}

\section{Introduction}

In recent years, specialty powder paints have been continuously developed to face the increasing demands of high standards in terms of aesthetic and functional performance of the industrial coatings. Powder coatings are widely used in different fields, from automotive to electrical industry, and represent more than $10 \%$ of the market [1]. Among functional coatings, the interest in protective and thermal insulating films for metallic substrates is increased, since they can feature simultaneously long lasting and energy saving characteristics.

The research main goal in this field is to improve not only the material but also the coating technologies, with particular regard to the process sustainability and costs (e.g., reduction in pollutant solvent-borne primer and expensive surface activation processes).

In this context, the interest in fluidized bed (FB) coating process is increased, because of the advantages it allows: significant savings and environmental safety, feasibility on complex geometries, and the need for basic equipment, which can be easily scaled up and fully automated.

The first application of this technology was in the 1970s, when FB coating in the earliest studies of Richart $[2,3]$ and Pettigrew $[4,5]$ was proved to be a cost-effective and environmental friendly alternative to traditional painting processes. Since then, more sophisticated FB processes were developed to coat also large volumes of small and complex shaped parts. In the past decade, electrostatic FB was applied by Ali and Inculet $[6,7]$ to deposit thermosetting powder coatings onto rotors. In addition, Leong et al. $[8,9]$ developed a wide range of analytical and numerical models to simulate the deposition process inside a FB of thermoplastic powders. More recently, Barletta et al. looked into FB coating process using new generation of coatings materials and investigating the relationship among process parameters, FB hydrodynamic behaviour, and material properties $[10,11]$. Understanding of the physical mechanisms involved in the deposition process and the development of operational maps which are very useful to the practitioners for automation and control were depicted in those analyses [12].

Despite the increasing scientific interest in the FB, such technology is still poorly used in the industrial practice because of being troublesome in coating of complex shaped parts, expensive downtime during color change, and drawbacks in the abatement of the elutriated powders. Thus, FB is so far devoted to specific application where specialty 
combination coatings should be implemented. In this respect, the present paper discusses the application of fluidized bed to produce specialty wood-polymer protective coatings to functionalize metallic substrates. In particular, aluminum slabs were preheated and dipped in a cloud of fluidized wood powder and, subsequently, polyphthalamide powder to generate a multilayered insulating coating. The effect of the main process parameters, such as process time and temperature, number and composition of superimposed layers, and the coating properties in terms of morphology, wear resistance, scratch adhesion, and thermal insulation, was looked into. For this purpose, morphological tests by combined use of contact gauge profiler and SEM (Scanning Electron Microscope) and wear and scratch tests were carried out. In addition, infrared thermography was used to evaluate the thermal properties of the insulating coatings. The experimental findings showed that the hybrid woodenpolymeric coatings are characterized by a good appeal. They were well adhered to the substrate, showing good protection of the underlying substrate and remarkable wear endurance. Further, IR thermography showed the effectiveness of the wood powders in lowering the thermal conductivity of the applied material, thus inducing a significant improvement in the thermal insulation of the investigated coatings.

\section{Materials and Methods}

2.1. Materials. Aluminum samples, $40 \times 40 \times 6 \mathrm{~mm}^{3}$ in size, were submitted to FB coating process. Polyphthalamide (PPA $571 \mathrm{H}$, Plascoat Systems Limited, Farnham, Surrey, UK) and beech wood powders (La.So.Le. Est, Percoto (UD), Italy), $20 \mu \mathrm{m}$ in diameter, were chosen as coating materials.

2.2. Processing. The fluidized bed shown in Figure 1 was used to deposit the hybrid coatings. It was composed of an air supply system, a vertical fluidization column $(100 \mathrm{~mm}$ in diameter and $1 \mathrm{~m}$ in height), and a homogenization section, which produced a uniform fluidization in the bed.

Four coating types, differing in terms of numbers of layers they were composed of, were developed (types A-D, Figure 2). The coating process for type A samples was scheduled as follows: (i) the sample was first washed in an ultrasonic bath of ethanol for $5 \mathrm{~min}$ and, then, dipped for $5 \mathrm{~s}$ inside a bath of diluted acrylic resin (DPEBA $0.5 \mathrm{wt} . \%$ ) in isopropyl alcohol; (ii) the precoated sample was preheated at $40^{\circ} \mathrm{C}$ and dipped inside a fluidized bed of wood powders $\left(5 \mathrm{~m}^{3} / \mathrm{h}\right.$ flow rate, bubbling regime) for $10 \mathrm{~s}$, achieving their partial adhesion on the acrylic basecoat; (iii) the resulting layer was left to cure for $10 \mathrm{~h}$ at environmental condition and the excess of wood powders was removed by air flux; (iv) the wood coated sample was heated at $170^{\circ} \mathrm{C}$ for $10 \mathrm{~min}$ in a convection oven and dipped and raised out, three times, inside a fluidized bed of polyphthalamide powders $\left(8 \mathrm{~m}^{3} / \mathrm{h}\right.$ flow rate, bubbling regime) for $0.5 \mathrm{~s}$ to allow the growth of a thick enough polymeric coating. The sample was postheated at $170^{\circ} \mathrm{C}$ for $5 \mathrm{~min}$ in a convection oven to allow the unmolten polymeric powders to coalesce and level until a smooth film was formed. The rest of the samples (i.e., types B, C, and

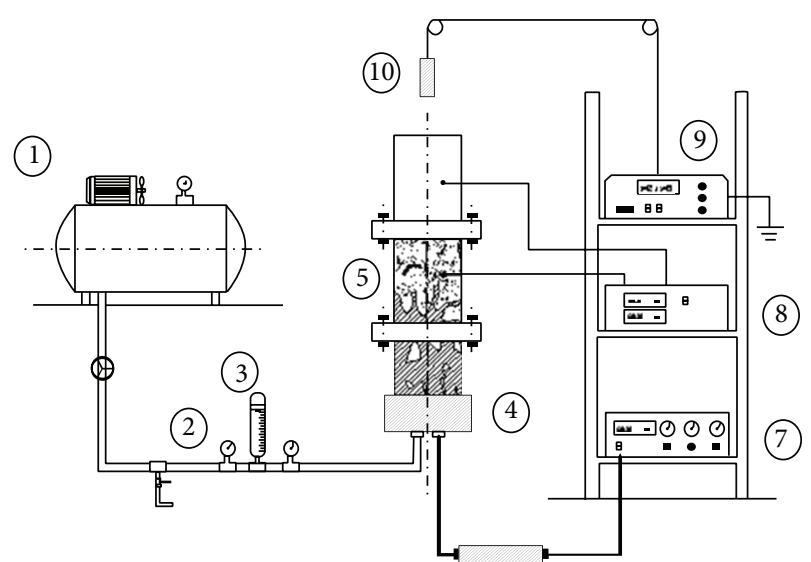

(6)

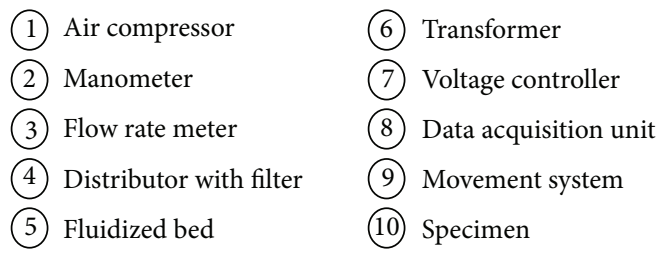

Figure 1: Fluidized bed apparatus.

TABLE 1: Coating procedure (stages i, ii, iii, and iv described in Section 2).

\begin{tabular}{cccccc}
\hline Coating type & Type A & Type B & Type C & Type D & Ref. \\
\hline \multirow{6}{*}{ Coating stages } & i & i & i & i & iv \\
& ii & ii & ii & ii & \\
& iii & i & i & i & \\
& iv & iii & ii & ii & \\
& & iv & iii & i & \\
& & & iv & iii & \\
\hline
\end{tabular}

D) were manufactured according to the aforementioned procedure, although some steps of the process were reiterated according to the details summarized in Table 1. A standard sample was manufactured by hot-dipping fluidized bed of the aluminum substrate inside the polyphthalamide powders for comparative purposes.

2.3. Characterization. Coating thicknesses and their uniformity were evaluated by a digital palmer (Mitutoyo, 293816), performing five measurements equally distributed over the coated surface. The coating morphology was analyzed by contact inductive gauge of a surface profiler (TalySurf CLI 2000, Taylor Hobson, Leicester, UK). In particular, 50 profiles, $15 \mathrm{~mm}$ long, were stored for each sample, with the resolution of $1 \mu \mathrm{m}$ along the measurement direction, covering an area $4 \times 4 \mathrm{~mm}^{2}$ in size. The acquired profiles were elaborated using the TalyMap 3.1 software, and the main roughness parameters were evaluated.

Scratch tests were performed on the insulating coatings, operating both in progressive mode and at constant 

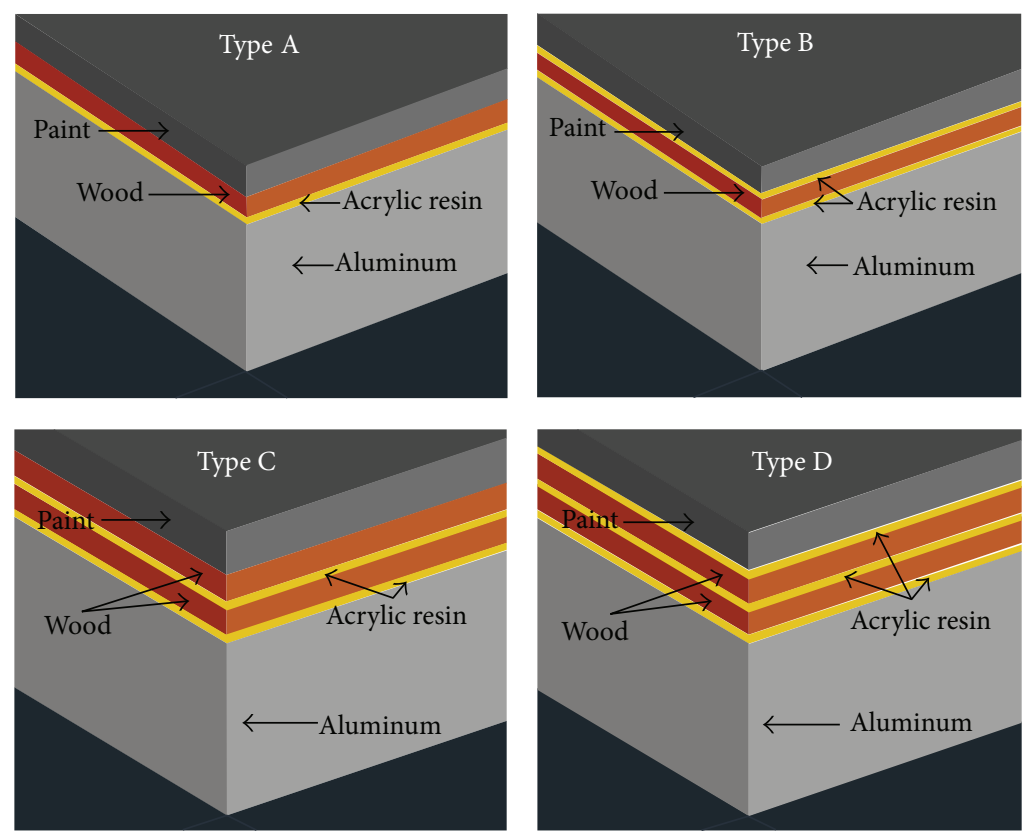

FIGURE 2: Scheme of the investigated coating systems.

load (Micro-Combi, CSM Instruments, Peseux, Switzerland), using a Rounded Conical Rockwell C diamond indenter, with $100 \mu \mathrm{m}$ tip radius. During the test, the indenter first profiled the surface applying a very low load and recording the starting surface profile (i.e., prescan). Subsequently, the tip penetrated the coating material moving at constant sliding speed and applying the load until the achievement of the scratch track (i.e., scan). Normal and tangential forces were recorded, accordingly. Finally, the indenter profiled the scratch pattern back at low load in order to monitor the change in morphology of the coating after its elastic recovery, storing the residual depth (i.e., postscan). In progressive mode, the sliding speed during the scan was $1 \mathrm{~mm} / \mathrm{min}$ and the applied load grew from $100 \mathrm{mN}$ to $30 \mathrm{~N}$ until the achievement of a scratch track $3 \mathrm{~mm}$ long. In the other tests, the indenter produced a track $2 \mathrm{~mm}$ long, applying a constant load of $20 \mathrm{~N}$, moving at $0.2,1,5,25$, and $100 \mathrm{~mm} / \mathrm{min}$ scratch speed, respectively.

The residual scratch pattern was rebuilt by the contact inductive gauge of the surface profiler in order to evaluate the size and geometry of the residual scratch pattern.

Wear endurance of the insulating coatings was assessed by ball-on-flat linear reciprocating tribological test (Tribometer, CSM Instruments, Peseux, Switzerland), using spherical counterpart (6 mm in diameter, 100Cr6 steel, $64 \mathrm{HRC}$ ). Five tests were performed on each coating by applying $3 \mathrm{~N}$ normal load and $4 \mathrm{~Hz}$ frequency and varying the sliding distance in a range of 5 to $500 \mathrm{~m}(5,10,25,100$, and $500 \mathrm{~m})$. The friction coefficients were recorded, as well. The residual worn patterns were rebuilt by the contact inductive gauge of the profiler (resolution $2 \mu \mathrm{m}$ ) in order to evaluate their average depth and the overall volume of the abraded material.

A Field Emission Gun-Scanning Electron Microscope (FEG-SEM Leo, Supra 35, Carl Zeiss SMT, Inc., Thornwood,
TABLE 2: Average thickness of coatings.

\begin{tabular}{lccc}
\hline Coating & $\begin{array}{c}\text { Insulating layer } \\
\text { thickness } \\
{[\mathrm{mm}]}\end{array}$ & $\begin{array}{c}\text { Paint thickness } \\
{[\mathrm{mm}]}\end{array}$ & $\begin{array}{c}\text { Average } \\
\text { thickness } \\
{[\mathrm{mm}]}\end{array}$ \\
\hline $\mathrm{A}$ & $1.436 \pm 0.073$ & $0.304 \pm 0.013$ & 1.741 \\
$\mathrm{~B}$ & $1.437 \pm 0.079$ & $0.312 \pm 0.023$ & 1.749 \\
$\mathrm{C}$ & $1.483 \pm 0.063$ & $0.259 \pm 0.019$ & 1.742 \\
$\mathrm{D}$ & $1.465 \pm 0.1023$ & $0.284 \pm 0.022$ & 1.749 \\
Ref. & & $0.505 \pm 0.033$ & 0.505 \\
\hline
\end{tabular}

New York) was used to take high-resolution images of the coating morphologies as well as of the scratch and wear residual patterns.

Moreover, infrared thermography (IR camera CedipJade) was used to measure the heat diffusion within the sample to estimate the thermal insulation of the coatings. Before testing, the samples were coated with a thin layer of graphite to increase and make uniform the surface IR emissivity. They were located on a hot plate at $80^{\circ} \mathrm{C}$ and the temperature acquisition was started. The distance between IR camera and plate was $300 \mathrm{~mm}$. IR thermography was used to characterize the thermal properties of types A and C coatings, neglecting the difference induced by the presence of the acrylic layer in types B and D coatings in terms of thermal properties (i.e., the acrylic resin was mainly used to increase the powder adhesion during FB process).

\section{Results and Discussion}

3.1. Visual Appearance and Morphology. The thickness of the coating systems investigated is reported in Table 2. The hybrid 

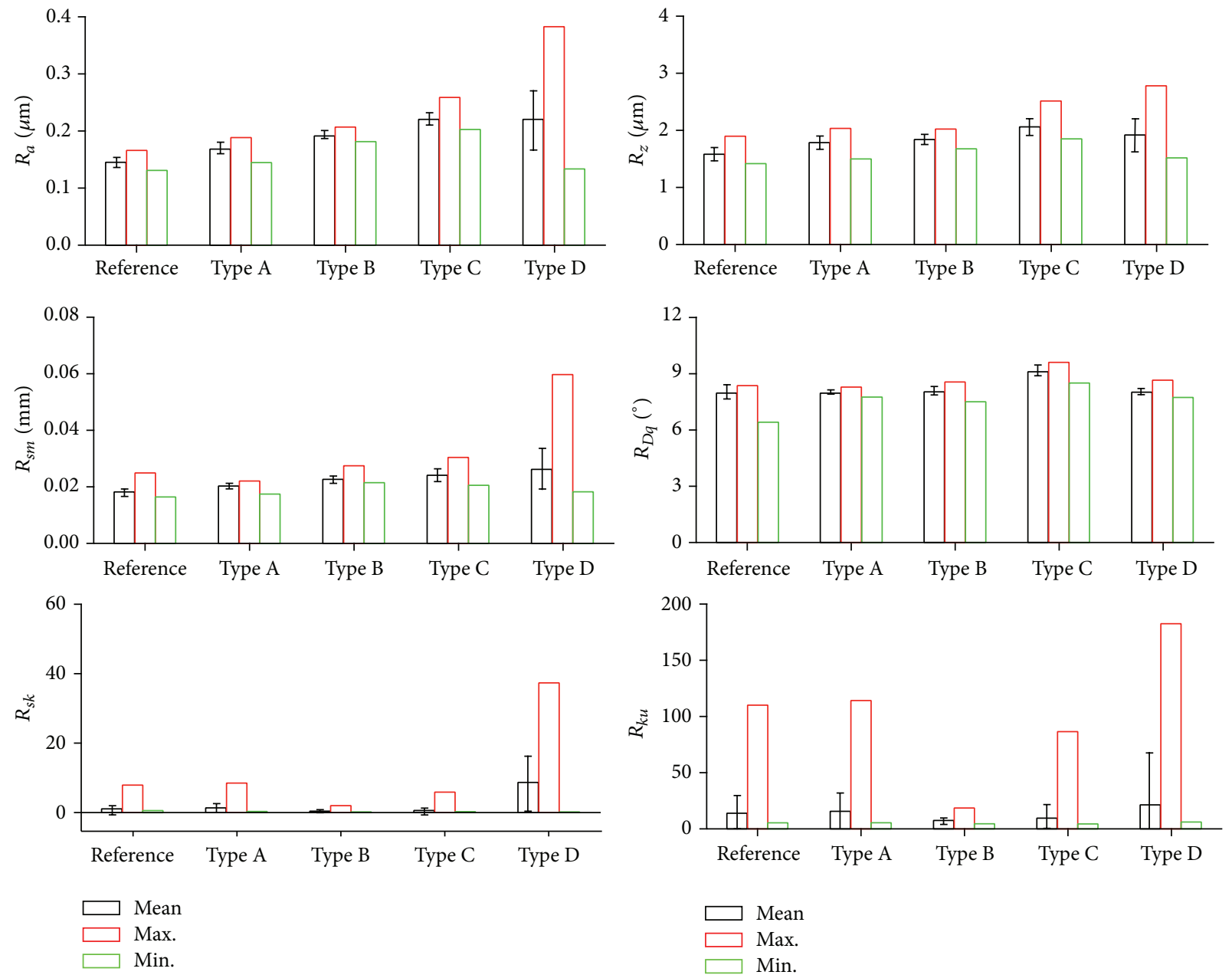

FIGURE 3: Roughness parameters for insulating coatings A-D and reference coating (Ref.).

wooden-polymer coatings are very thick, approximately $1.75 \mathrm{~mm}$ regardless of the strategy involved in the coating buildup (i.e., systems A-D). In all the investigated systems, the amount of wooden material averaged approximately 1.4$1.5 \mathrm{~mm}$, whilst the polymeric layers accounted for only $0.25-$ $0.30 \mathrm{~mm}$, acting as binder and conferring toughness and ductility to the coating system and adhesion by mechanical locking to the underlying aluminium substrate. The coating system taken for comparative purposes is a thinner singlelayered polymeric coating (made only from polyphthalamide). In this case, the coating thickness averaged approximately $0.5 \mathrm{~mm}$.

Figure 3 summarizes the amplitude roughness parameters of the investigated coatings. The presence of the wooden particles dispersed inside the polymeric binder makes the coatings coarser, with the average roughness $R_{a}$ varying from 0.14 of the pure polyphthalamide coating to $0.17-0.22 \mu \mathrm{m}$ of the wooden-polymer composite coating systems. The higher the number of wooden layers inside the coating systems, the coarser the coatings result. Such experimental findings might be ascribed to the behaviour of the wooden powders during the coating buildup. The pure polymeric coating (i.e., reference sample) is deposited by hot-dipping fluidized bed. The process involves only polymeric powders, which coming in touch with the preheated metal substrate melt, coalesce, and level, until a very smooth layer of "plastic" material is formed. This result is in agreement with Lee et al. [13], first, and Andrei et al. [14], later, which established the correlation between the surface structure buildup of the coating and the baking process in convection oven. In particular, they related the surface leveling of powder coatings to the evolution of the viscosity with time and temperature. The higher the baking temperature would be, the faster the initial decrease in resin viscosity and therefore its capability to melt and level over a flat substrate would be. However, the development of smooth finishes after postheating of polyphthalamidebased coatings deposited by electrostatic FB was detailed by Barletta et al. [15] in an earlier study, as well. Differently, the wooden particles dispersed inside the polymeric material in the coating systems A-D do not melt neither when they come in touch with the hot metal substrate nor during the postheating. They keep their initial nearly spherical shape, reducing in diameter as result of the expulsion of the water retained in them by water evaporation 


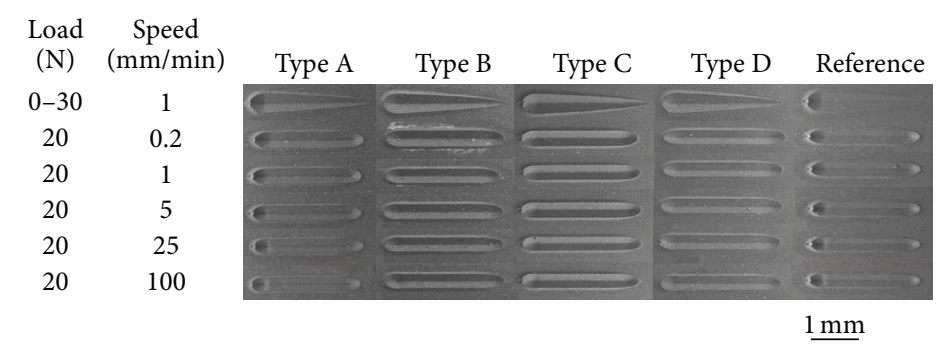

FIGURE 4: SEM images of the residual scratch patterns.
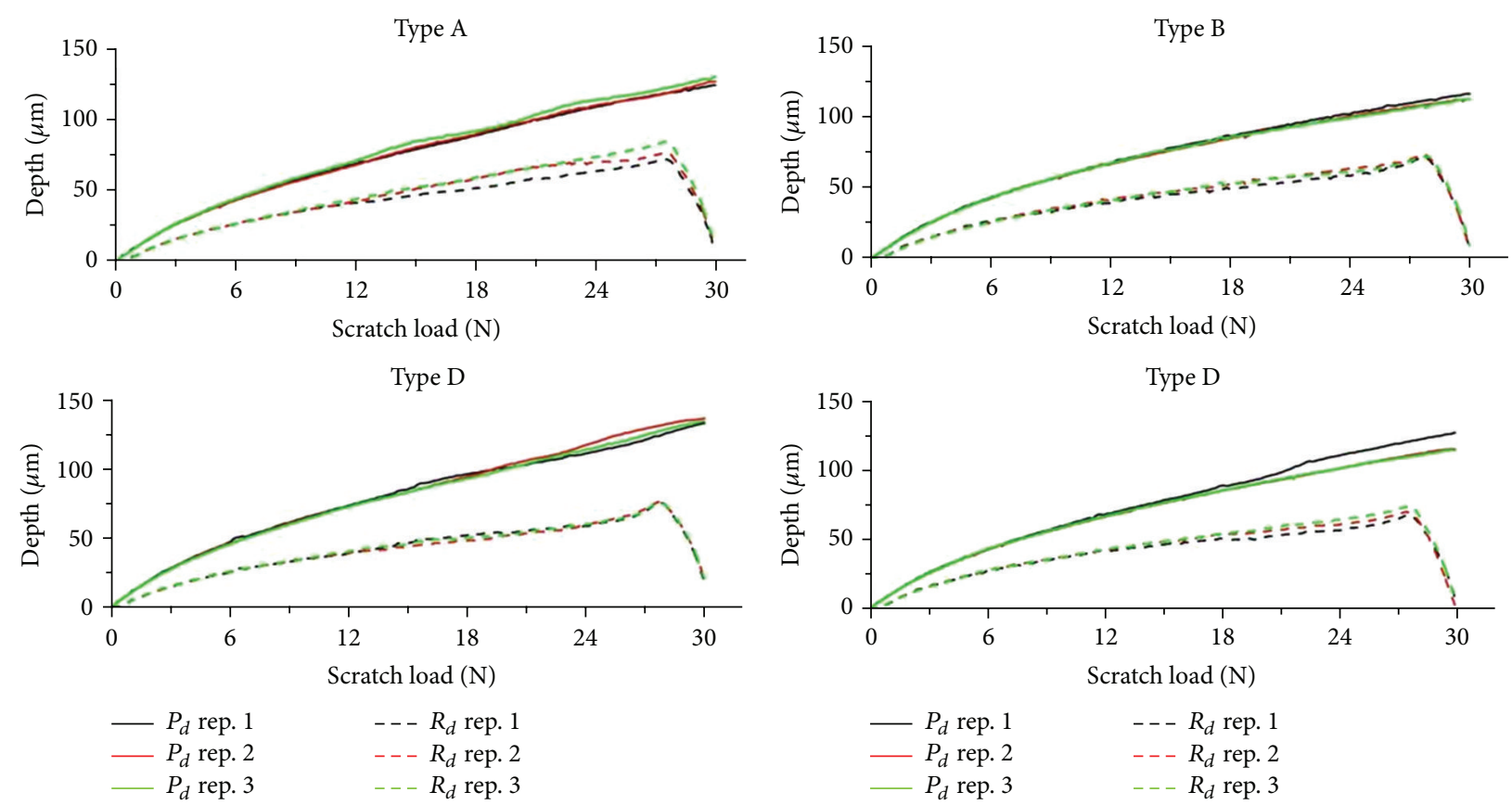

Figure 5: Penetration depth $P_{d}$ and residual depth $R_{d}$ in progressive mode scratch tests (Rep. 1, 2, and 3 are the three replications of the scratch tests performed on the different samples A-D).

at high temperature. The wooden particles become smaller and, accordingly, influence marginally the morphology of the resulting coating systems. Yet, the increasing presence of wooden particles inside the multilayer coatings (i.e., from samples A to D) is reflected in a corresponding increasing in the surface roughness. In addition, in all the woodenpolymer composite coatings, the last layer is made from polyphthalamide, which, as said before, levels very well and establishes a smooth morphology as a result of the powder melting and coalescence at high temperature. Therefore, the variation in the morphology of all the coating systems is strongly affected by the leveling effect of the thermoplastic binder (i.e., the topcoat).

3.2. Micromechanical Response. Figure 4 shows the SEM images of the residual scratch patterns. No relevant damage or macrocracks appear to affect the coating surfaces. The residual scratch patterns are characterized by a massive pileup at their sides and ahead of the last position of contact between the indenter and the coating surface at the end of the progressive load scratch test. This is the evidence of the ductility of the coating system, despite the presence of the loose wooden particles inside the ductile polymeric binder. Indeed, the relationship between coating ductility and its capability to comply with the indenter during the progressive load scratch test was already investigated in the pertinent literature [16]. Jardret et al. emphasized how ductile polymeric substrates were definitely more prone to deform under high load scratch tests, thus generating the formation of plastic accumulation all around the residual scratch pattern. Brittle materials, being not compliant with the penetrating indenter and resistant to high deformation in plastic field, were more subject to form cracks and fail during the scratching procedure $[17,18]$.

The good scratch resistance of the coating systems is confirmed by the trends of the penetration (i.e., depth of the scratch pattern during the application of the load) and residual (i.e., depth of the scratch pattern after the release of the load and the elastic recovery of the coatings) depths reported in Figures 5 and 6. In Figure 5, the results of progressive scratch tests are shown. The maximum penetration depth averaged approximately $120-130 \mu \mathrm{m}$ and it is not dependent on the number of layers the coating was made 

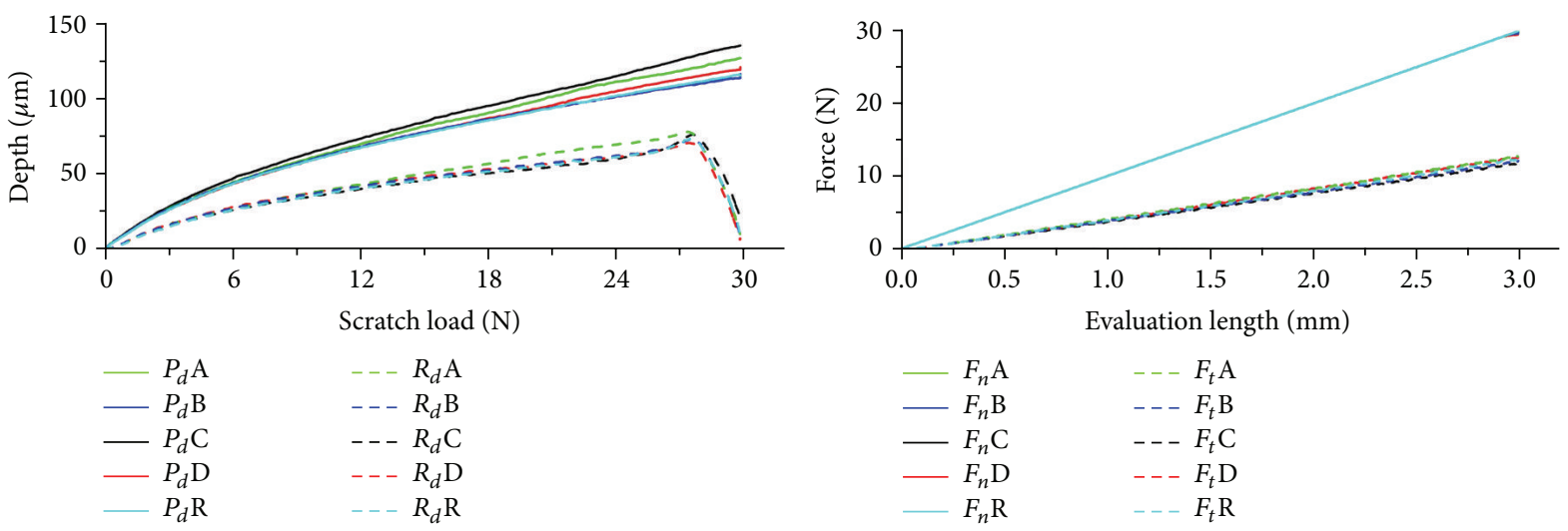

FIGURE 6: Results of progressive scratch tests: comparison between coatings A-D and reference (R).
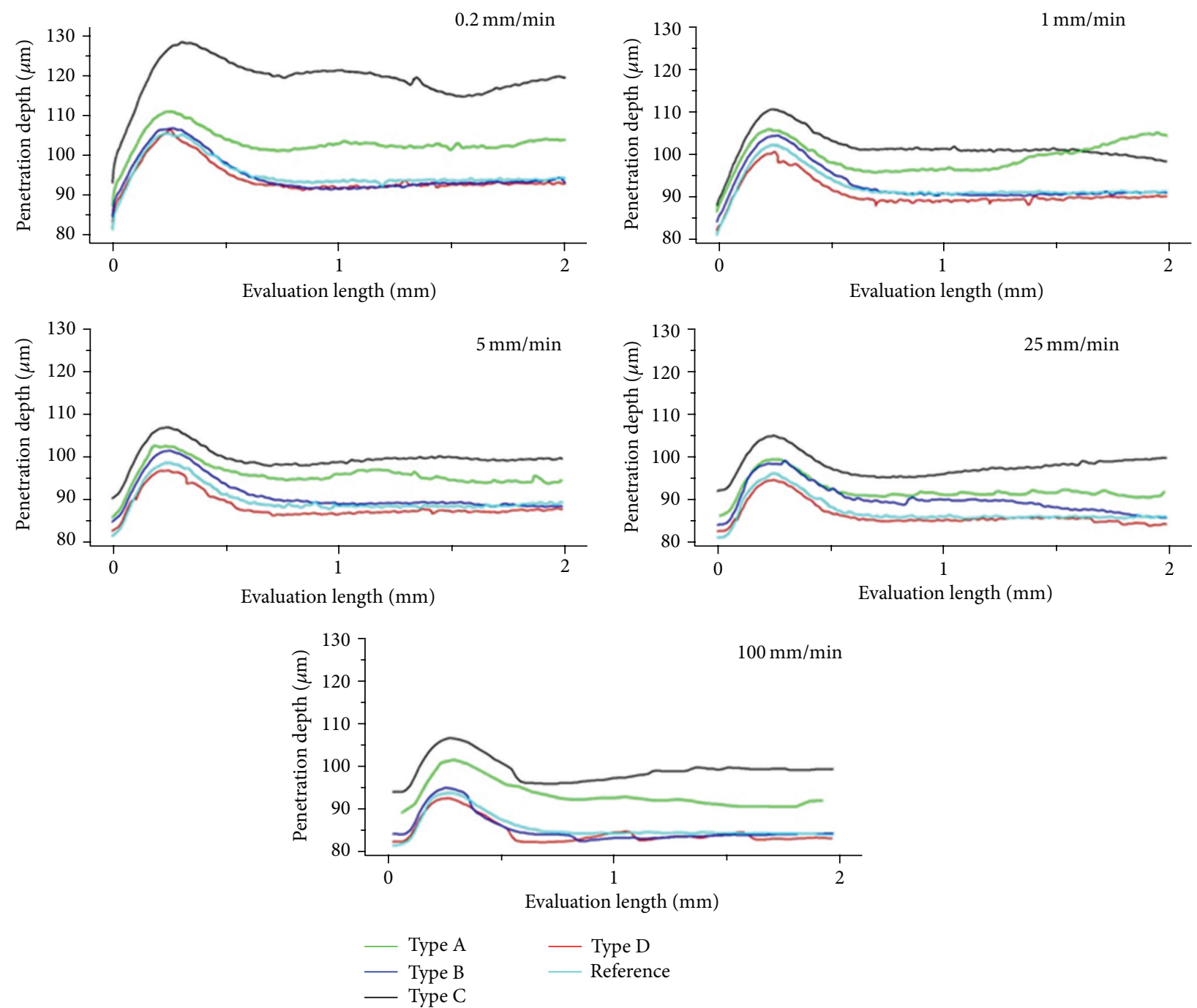

Figure 7: Penetration depth in scratch tests at constant load and different sliding speed.

from. A comparison between the protective coatings A-D and the coating $\mathrm{R}$, used for comparative purpose, is shown in Figure 6, which report the trends of the penetration and residual depths as well as the corresponding trend of the scratch forces. The trends of the penetration and residual depth were very similar. They show a power-law like increase in the depth according to the applied load. Neither sudden increase in the penetration depth or irregular wave-like 

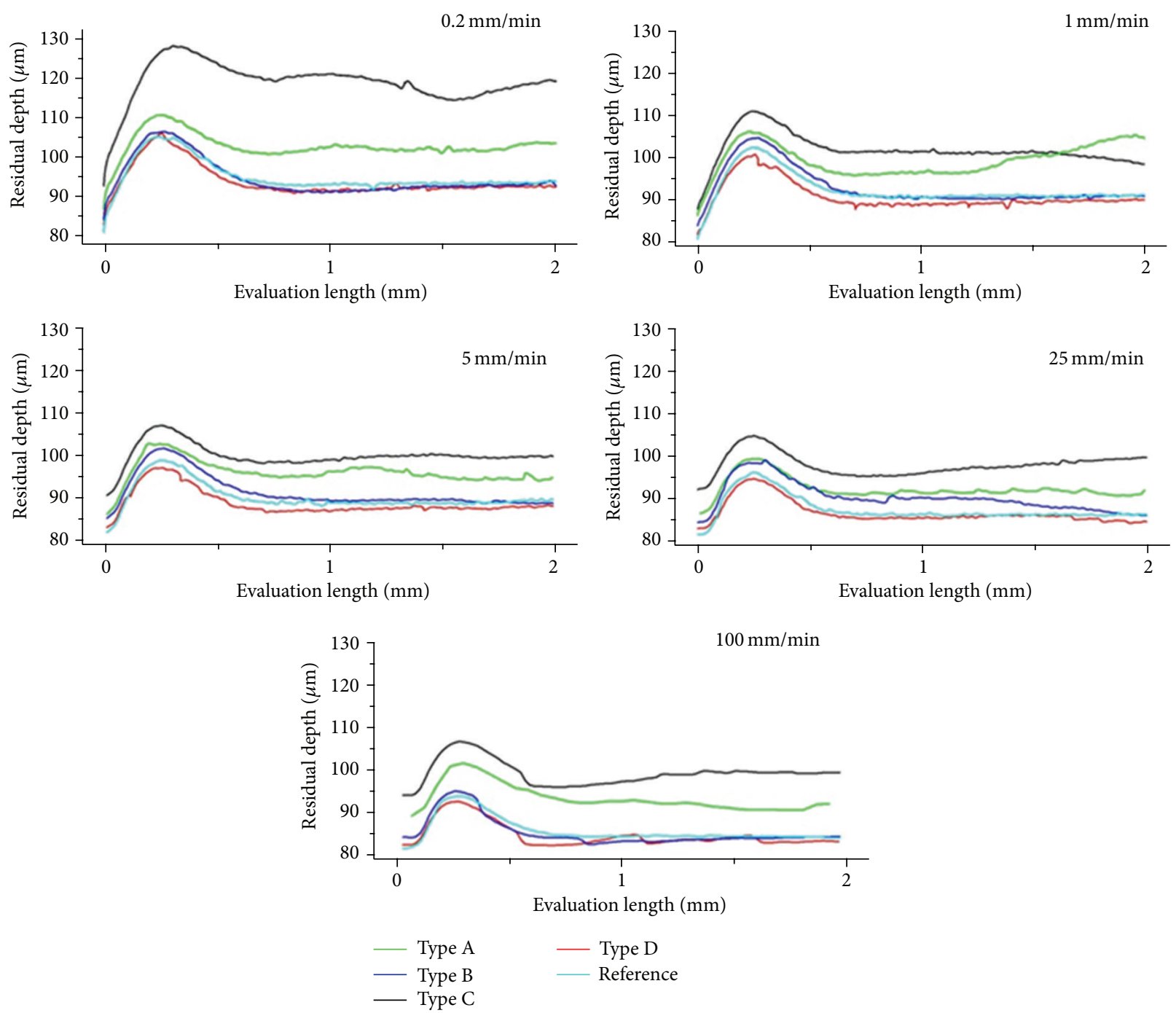

Figure 8: Residual depth $R_{d}$ in scratch tests at constant load and different sliding speed.

trends nor increasing scattering characterizes the trends of the penetration and residual depths, thus confirming the lack of any significant damage on the coating surface and inside the scratch patterns. The small bumps and the concurrent decreasing branches at the end of the residual scratch patterns are evidence of the large pileup, which is formed at the end of the scratch pattern around the last position of contact between the advancing indenter and the coating surface. However, despite the massive ploughing phenomena and the accumulation of plastic displaced material at the end of the scratch patterns, no damage by conformal cracking is visible inside the scratch pattern and ahead of the pileup. This is evidence of the extraductility of the coating materials which is conferred by the thermoplastic binder used (i.e., the polyphthalamide) in agreement with what was found by Barletta et al. [19-21], which showed an improved ductility for polyphthalamide coatings deposited by FB.

Those coatings, being thicker, were found to be more compliant to absorb the stress induced in the polymeric material by the penetrating indenter, deforming more extensively but failing less or not at all. The trends of the scratch forces, being very regular and continuous, support the aforementioned considerations.

Figures 7 and 8 show the trends of penetration and residual depths recorded during the scratch tests carried out at constant load $(20 \mathrm{~N})$ and different sliding speeds $(0.2,1$, $5,25$, and $100 \mathrm{~mm} / \mathrm{min})$. As expected, all the investigated coating systems agree with the data available in the pertinent literature [16] and exhibited a stiffer response at any time faster sliding speed was set. In addition, the coating systems $\mathrm{A}$ and $\mathrm{C}$ exhibited higher average penetration depths. This result might be ascribed to the lack of the intermediate acrylic-based layer between the topcoat and the underlying wooden-rich layer. This could result in reduced interfacial adhesion and stiffness.

The residual scratch patterns of the investigated coating systems were rebuilt and the volumes of penetration during the application of the scratch load as well as the volume of the ditch and pile after the release of the load were reported together with the elastic, plastic, and fracture contributions 

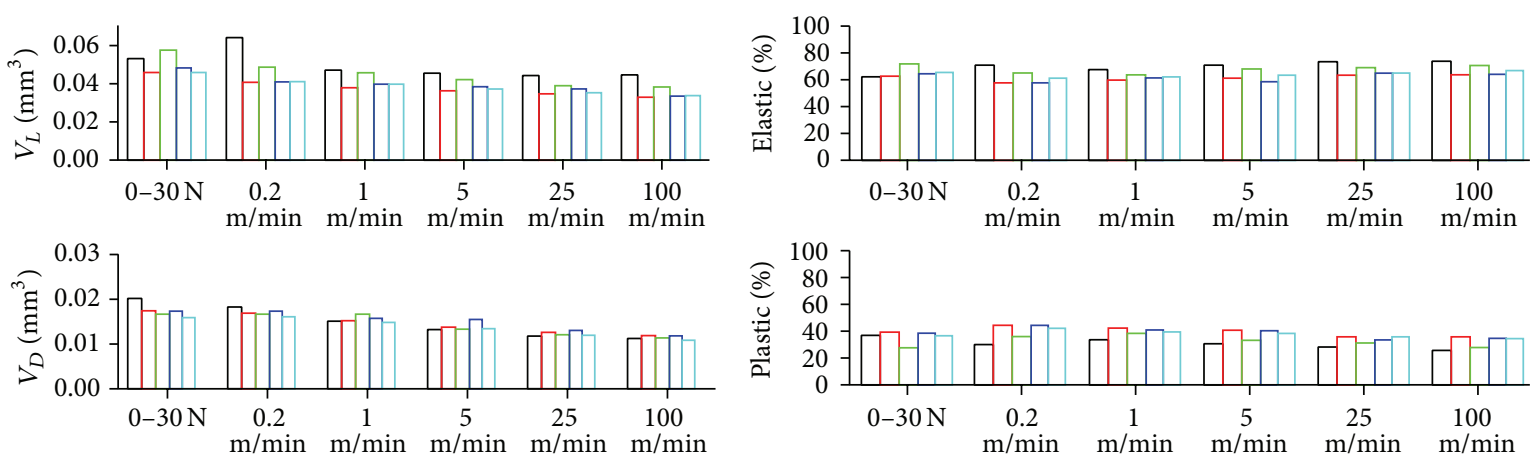

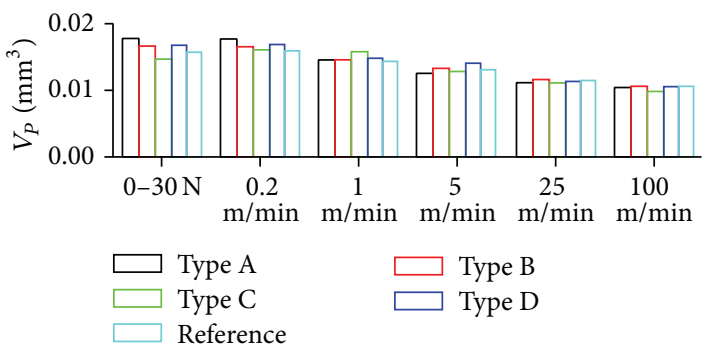

(a)

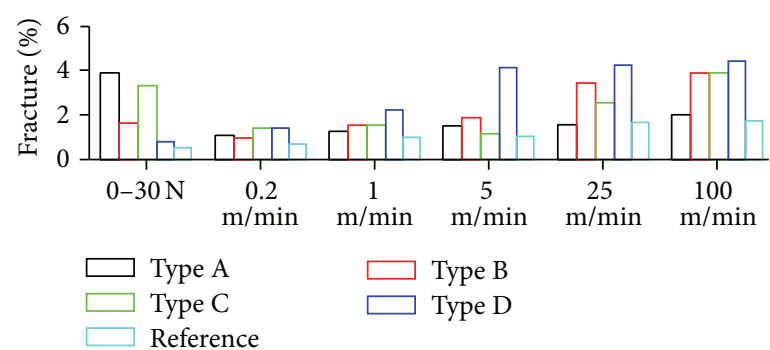

(b)

FIGURE 9: Analysis of residual scratch patterns: (a) volume of pile $\left(V_{P}\right)$ and ditch $\left(V_{D}\right)$; (b) deformation contributions.

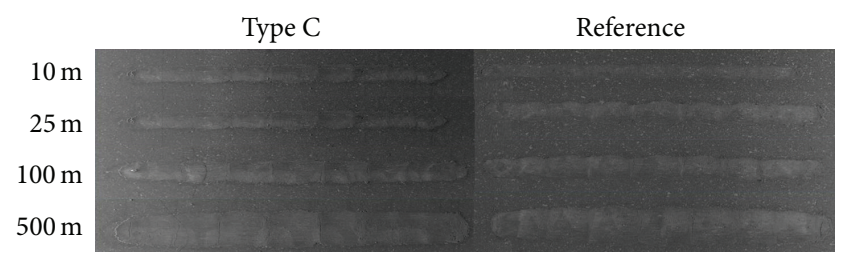

FIGURE 10: SEM images of worn patterns at $500 \mathrm{~m}$ sliding distance.

(Figure 9). The results showed the good recovery capability of all the investigated coatings whatever the setting of the scratch parameters. In addition, the experimental data confirmed how the coatings became progressively stiffer (i.e., progressively higher percentage of plastic contribution) and more brittle (i.e., progressively higher percentage of fracture contribution) when higher sliding speed was set during the constant load scratch test.

3.3. Wear Response. Figures 10 and 11 report the results of wear tests carried out on the developed coatings. In Figure 10, the SEM images show the topography of the residual wear patterns, composed of subsequent peaks and large valleys between them. Such topographic feature of the wear track is attended at any time the coating material is ductile and behaves according to the mechanism of the stick and slip. This means that, during the tribological test, the counterpart exerts its action on the coating surface trying to penetrate deep inside it. Nevertheless, when the advancing counterpart penetrates the surface, a front of plastically deformed material is displaced in front of it, thus opposing growing resistance to the penetration and refraining the indenter from

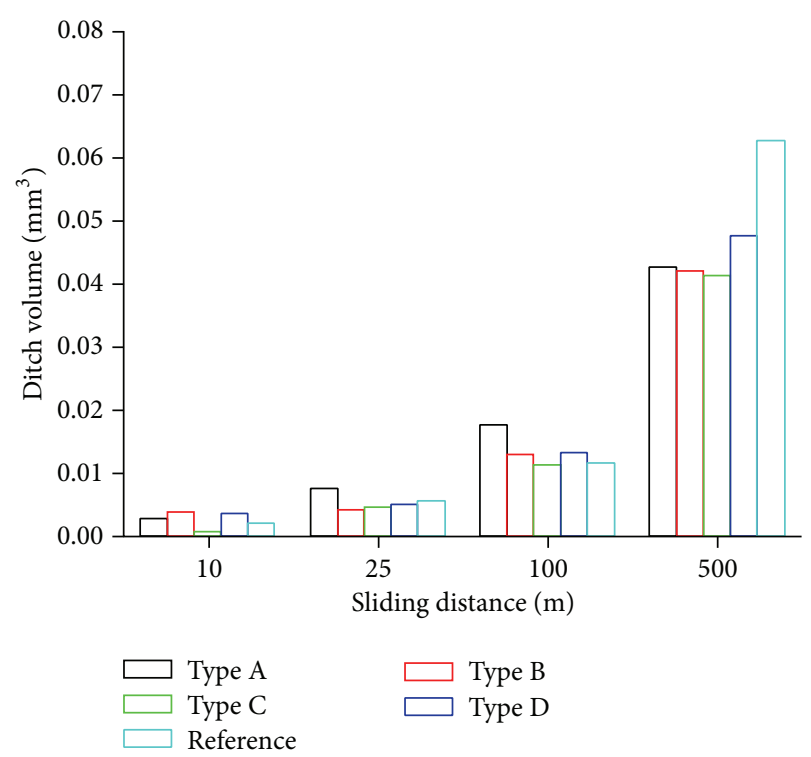

FIGURE 11: Wear tests: volume of abraded material.

penetrating further inside. Under such circumstance, a significant compressive residual stress is generated in front of the advancing counterpart and a tensile one at its back. If the compressive residual stress would overcome the ultimate stress of the coating material, they would induce a fracture in it in agreement with the failure mechanisms by Bull et al. [17]. In the present case, no fracture is present. This is the evidence that the counterpart, finding an increasing resistance ascribed to the plastically displaced material accumulated in front of it, jumps over the plastic formation. In this way, the stresses 


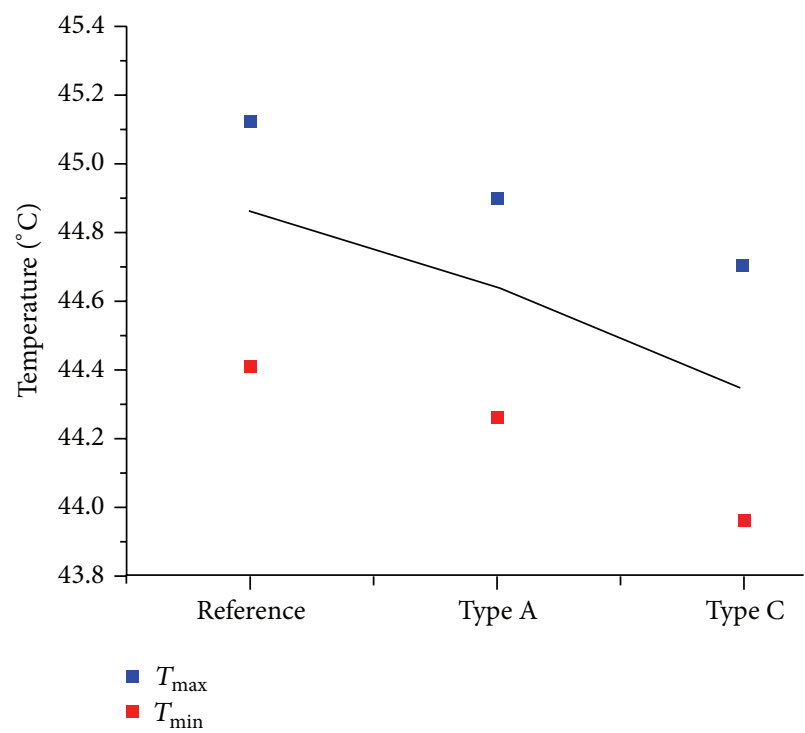

(a)

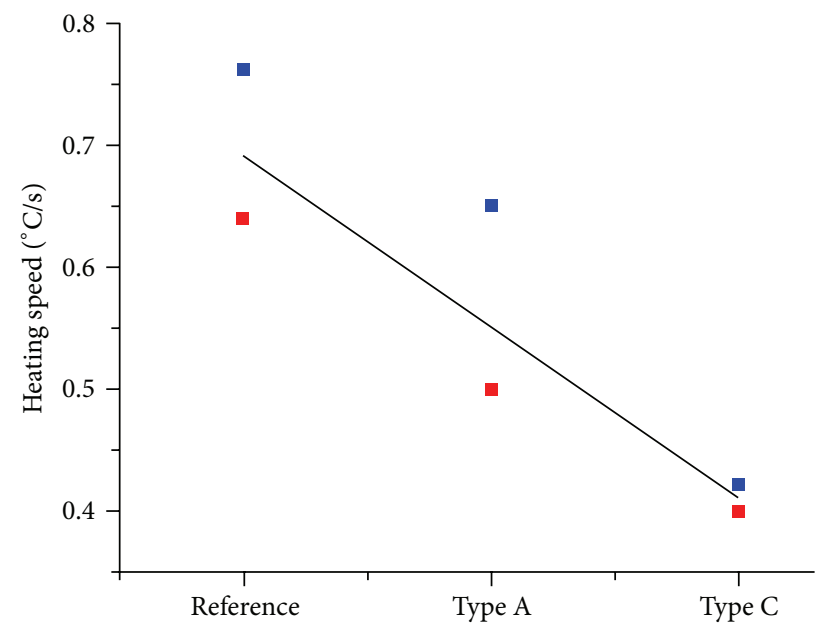

- Speed max.

- Speed min.

(b)

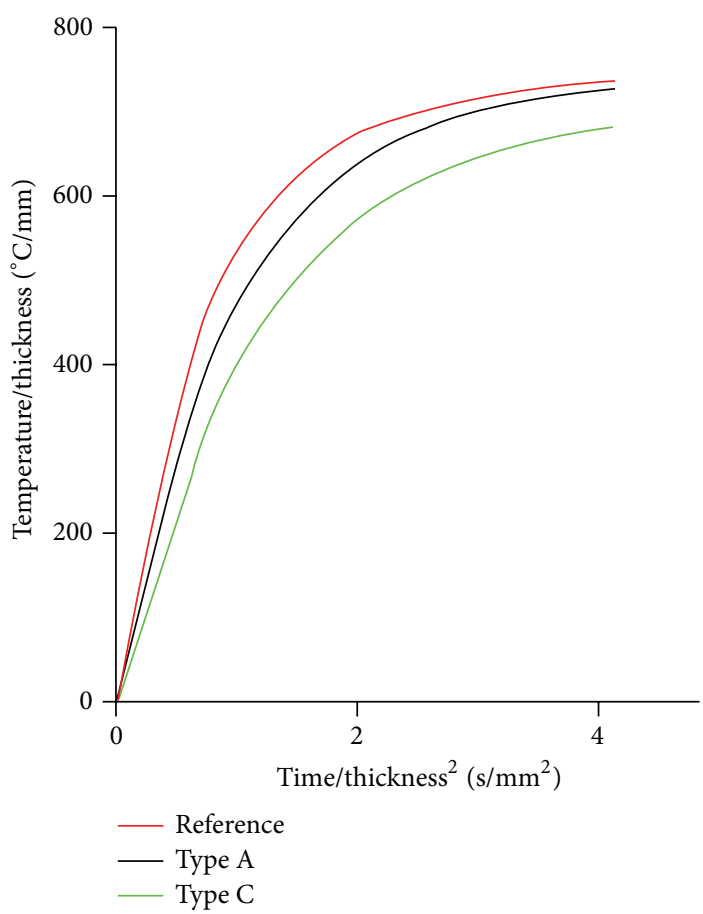

(c)

FIGURE 12: Analysis of the coating properties through IR thermography.

accumulated inside the coating material are instantaneously released and no damage takes place inside the coating. However, the counterpart is free to slide over the coating surface and penetrate it again.

Accordingly, the aforementioned stick-slip mechanism is reiterated once again, thus inducing the typical large peaksto-valleys topography, which characterizes all the residual wear patterns. Stick and slip phenomena were often observed on ductile organic coatings and bulk materials, when submitted either to progressive and continuous load scratch tests or to sliding and rotating tribological tests as reported in the literature $[22,23]$.

Figure 11 reports the volumes of the abraded material for all the investigated coating systems. The trends roughly follow Archard's law. Wear performances of the types A-D coatings are roughly similar and until $100 \mathrm{~m}$ as sliding distance during the tribological tests, the comparative coating $\mathrm{R}$ behaves the same, as well. The amount of abraded volume is initially very low for all the investigated coatings and then increases according to the mechanism of the initial running-in stage 
where the coating materials become compliant with the counterpart. This stage in the abraded volume is then followed by the steady stage where the coating material is worn out in a steady and uniform way $[24,25]$. No sudden increase in the abraded volumes is found during the first $500 \mathrm{~m}$ except for the pure polyphthalamide coating. In fact, after $500 \mathrm{~m}$ sliding distance, the wear endurance of the woodenpolyphthalamide coatings was found to be slightly better than that of the mere polyphthalamide coating. This result can be ascribed to the difference in the coating thickness and to the presence of the hard and tough wooden particles, which confer extra stability and resistance to the overall coating systems. The wooden particles act as reinforcement to the organic binder, thus withstanding the action of the metallic counterpart and reducing the amount of abraded material. In addition, the pure polyphthalamide coating is thinner and this means less compliance to absorb the stress of the counterpart during the dry sliding tribological tests. Therefore, it can be inferred that the coating starts to exhibit the transition to a last stage of wear response, that is, the quick increase in the abraded volume as a result of the onset of catastrophic material failure [25]. In contrast, the first two wear stages were clearly observed on the wooden-polymeric material, but the third stage (the potential pattern towards the catastrophic failure of the coating) was not observed at all (i.e., maybe, as a result of the too short sliding distance).

3.4. IR Thermography. Figure 12 shows the results of IR thermography. The performance of the coatings $\mathrm{A}$ and $\mathrm{C}$ was tested, being very similar from a thermal point of view to coatings $\mathrm{B}$ and $\mathrm{D}$, respectively. The coating temperature recorded during the tests is shown in Figure 12(a), where the heating speed was obtained by dividing the temperature by the acquisition time (Figure 12(b)). In Figure 12(c), according to the theory of temperature distribution within a thermally insulated solid of uniform thickness, the temperature variation was divided by the thickness, while the acquisition time was divided by the thickness raised to the second power. Accordingly, it may be noted how type C coating allowed better insulation properties. This evidence could be related to the increased presence of wood powders, which conferred superior thermal insulating performance to this coating system.

\section{Conclusions}

In the present investigation, the capability of FB coating process to manufacture coatings based on woodenpolyphthalamide composite material is looked into.

An unprecedented technology to build multilayer insulating coatings by hot-dipping in a fluidized bed of dry particles and by wet dipping inside a liquid resin is proposed. As a result, well adherent and wear resistant multilayer coatings were obtained.

Micromechanical and tribological performances of the coating systems are related to the coating design and manufacture. Coatings types B and D exhibited better scratch response under constant load, where they showed a stiffer behaviour whatever the sliding speed of the indenter. Coatings types $\mathrm{A}$ and $\mathrm{C}$ were found to be less responsive to constant load scratch test as a result of the lack of the intermediate acrylic-based layer between the topcoat and the underlying wooden-rich layer, which partially compromised their scratch response. Wear response was substantially not dependent on the involved coating systems during the beginning of the tribological tests. The abraded volume roughly followed Archard's law and it was fairly low at the beginning of the test for all the samples to increase significantly after long sliding distance. After long distance, the better wear response of the wood-reinforced resin came out as a result of the better stability and stoutness ensured by the dispersed wood particles. Thermal insulation properties were very straightforward. They were found to significantly increase at any time new wooden layers are added over, thus leading to thicker and good-performing coating systems.

Accordingly, the experimented coating procedure, which is simple and cost-effective, could be profitable if used by practitioners to manufacture coating materials suitable especially for metal fixtures where a good protection against scratch and wear as well as a high degree of thermal insulation is strictly required. In addition, this class of coatings can be used in all those industrial applications where a robust coating system characterized by good insulation properties is required for energy saving related issues.

\section{Conflict of Interests}

The authors declare that there is no conflict of interests regarding the publication of this paper.

\section{References}

[1] P. G. de Lange, Powder Coatings, Chemistry and Technology, Vincentz Network, Hannover, Germany, 2nd edition, 2004.

[2] D. S. Richart, "A report on the fluidized-bed coating systempart 1-fluidized bed variables and their influences," Plastics Design \& Technology, vol. 2, pp. 18-26, 1962.

[3] D. S. Richart, "A report on the fluidized-bed coating systempart 2: plastics for coating and their selection," Plastics Design \& Technology, vol. 2, pp. 26-34, 1962.

[4] C. K. Pettigrew, "Fluidized bed coating-part 1: effects of fluidized bed variables, substrate pretreatment and preheating method," Modern Plastics, vol. 44, pp. 111-117, 1966.

[5] C. K. Pettigrew, "Fluidized bed coating-part 2: effects of dipping, post-heating andcomplex geometrical variables," Modern Plastics, vol. 44, pp. 150-156, 1966.

[6] F. S. Ali and I. I. Inculet, "Modelling of electric fields during electrostatic coating of metallic substrate in fluidized beds," IEEE Transactions on Industry Applications, vol. 36, no. 5, 2000.

[7] F. Sharmene, "Electric field analysis of the tribocharged fluidized bed powder coating process," IEEE Transactions on Industry Applications, vol. 36, no. 5, pp. 1247-1250, 2000.

[8] K. C. Leong, G. Q. Lu, and V. A. Rudolph, "An upper bound solution for the coating thickness of cylinders in a fluidized bed," Chemical Engineering Science, vol. 54, no. 8, pp. 1145-1149, 1999. 
[9] K. C. Leong, G. Q. Lu, and V. Rudolph, "Modeling of heat transfer in fluidized-bed coating of cylinders," Chemical Engineering Science, vol. 56, no. 17, pp. 5189-5200, 2001.

[10] M. Barletta, G. Costanza, and R. Polini, " $\mathrm{Al}_{2} \mathrm{O}_{3}$ thin coating of AA 6082 T6 components using a fast regime fluidized bed," Thin Solid Films, vol. 515, no. 1, pp. 141-151, 2006.

[11] M. Barletta and V. Tagliaferri, "Electrostatic fluidized bed deposition of a high performance polymeric powder on metallic substrates," Surface and Coatings Technology, vol. 200, no. 14-15, pp. 4282-4290, 2006.

[12] M. Barletta, "Electrostatic fluidized bed (EFB) coating of heat sensitive and electrical insulating substrates with low-curing thermoset epoxy-polyester (EP) powders," Progress in Organic Coatings, vol. 56, no. 2-3, pp. 185-198, 2006.

[13] S. S. Lee, H. Z. Y. Han, J. G. Hilborn, and J. E. Månson, "Surface structure build-up in thermosetting powder coatings during curing," Progress in Organic Coatings, vol. 36, no. 1, pp. 79-88, 1999.

[14] D. C. Andrei, J. N. Hay, J. L. Keddie, R. P. Sear, and S. G. Yeates, "Surface levelling of thermosetting powder coatings: theory and experiment," Journal of Physics D: Applied Physics, vol. 33, no. 16, pp. 1975-1981, 2000.

[15] M. Barletta, A. Gisario, S. Guarino, and G. Rubino, "Development of smooth finishes in electrostatic fluidized bed (EFB) coating process of high-performance thermoplastic powders (PPA $571 \mathrm{H})$," Progress in Organic Coatings, vol. 57, no. 4, pp. 337-347, 2006.

[16] V. Jardret and P. Morel, "Viscoelastic effects on the scratch resistance of polymers: relationship between mechanical properties and scratch properties at various temperatures," Progress in Organic Coatings, vol. 48, no. 2-4, pp. 322-331, 2003.

[17] S. J. Bull, "Failure modes in scratch adhesion testing," Surface and Coatings Technology, vol. 50, no. 1, pp. 25-32, 1991.

[18] M. Barletta, A. Gisario, L. Lusvarghi, G. Bolelli, and G. Rubino, "On the combined use of scratch tests and CLA profilometry for the characterization of polyester powder coatings: influence of scratch load and speed," Applied Surface Science, vol. 254, no. 22, pp. 7198-7214, 2008.

[19] M. Barletta, A. Gisario, and G. Rubino, "Scratch response of high-performance thermoset and thermoplastic powders deposited by the electrostatic spray and "hot dipping" fluidised bed coating methods: the role of the contact condition," Surface and Coatings Technology, vol. 205, no. 21-22, pp. 5186-5198, 2011.

[20] M. Barletta, A. Gisario, F. Trovalusci, and S. Vesco, "Visual appearance and scratch resistance of high performance thermoset and thermoplastic powder coatings," Progress in Organic Coatings, vol. 76, no. 1, pp. 244-256, 2013.

[21] M. Barletta, S. Vesco, and F. Trovalusci, "Effect of the substrate and interface on micro-scratch deformation of epoxy-polyester powder coatings," Progress in Organic Coatings, vol. 74, no. 4, pp. 712-718, 2012.

[22] S. L. Zhang and J. C. M. Li, "Slip process of stick-slip motion in the scratching of a polymer," Materials Science and Engineering A, vol. 344, no. 1-2, pp. 182-189, 2003.

[23] S. L. Zhang and J. M. Valentine, "Stick-slip and temperature effect in the scratching of materials," Tribology Letters, vol. 12, no. 4, pp. 195-202, 2002.

[24] G. Straffelini, "A simplified approach to the adhesive theory of friction," Wear, vol. 249, no. 1-2, pp. 79-85, 2001.

[25] F. J. Martínez, M. Canales, J. M. Bielsa, and M. A. Jiménez, "Relationship between wear rate and mechanical fatigue in sliding TPU-metal contacts," Wear, vol. 268, no. 2-3, pp. 388-398, 2010. 

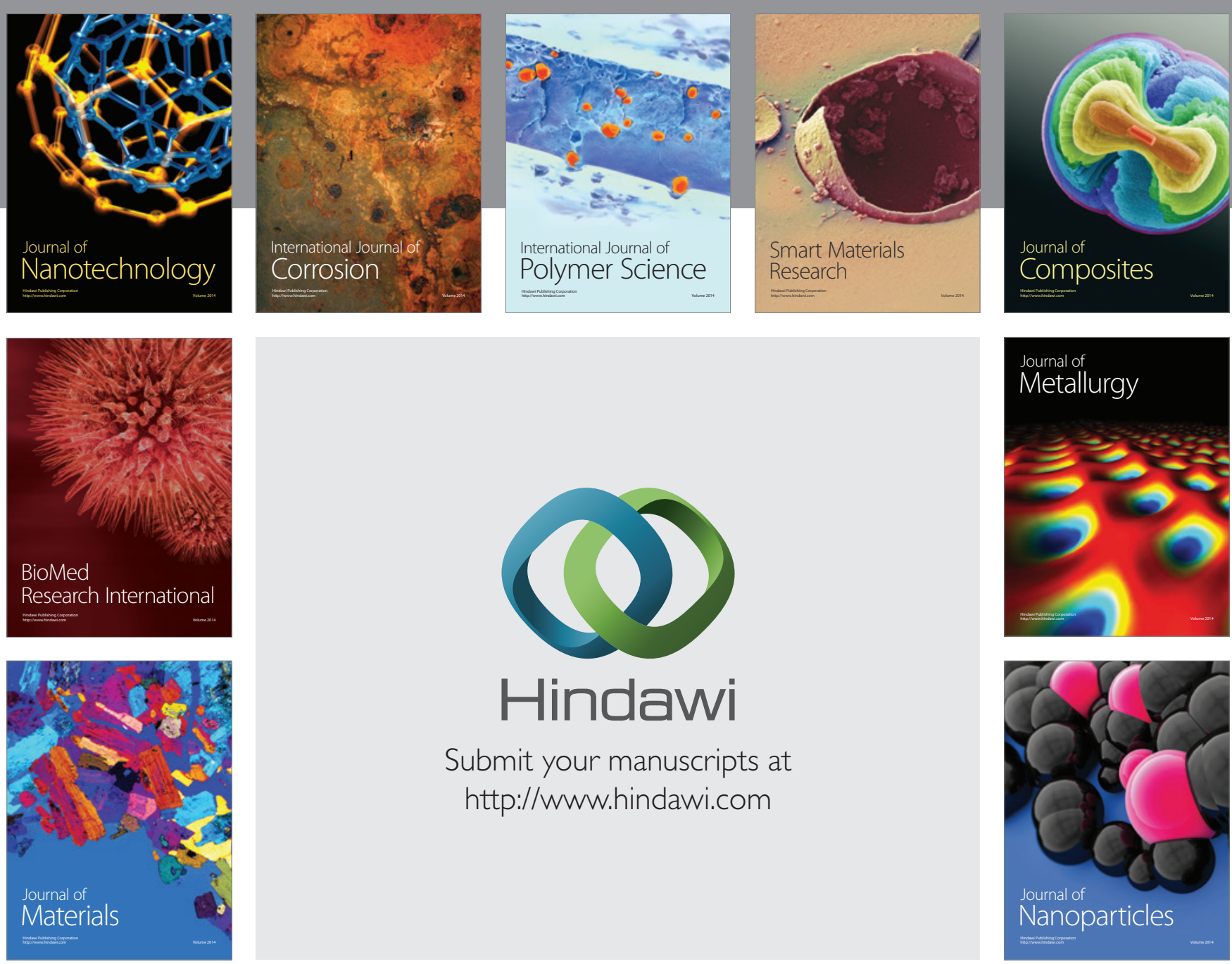

Submit your manuscripts at http://www.hindawi.com
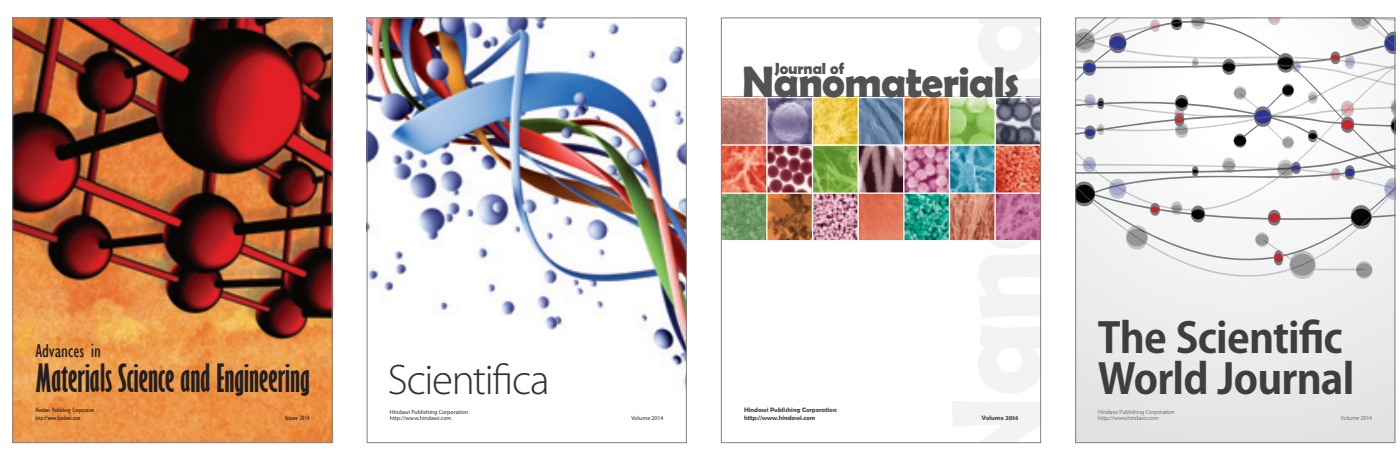

\section{The Scientific World Journal}
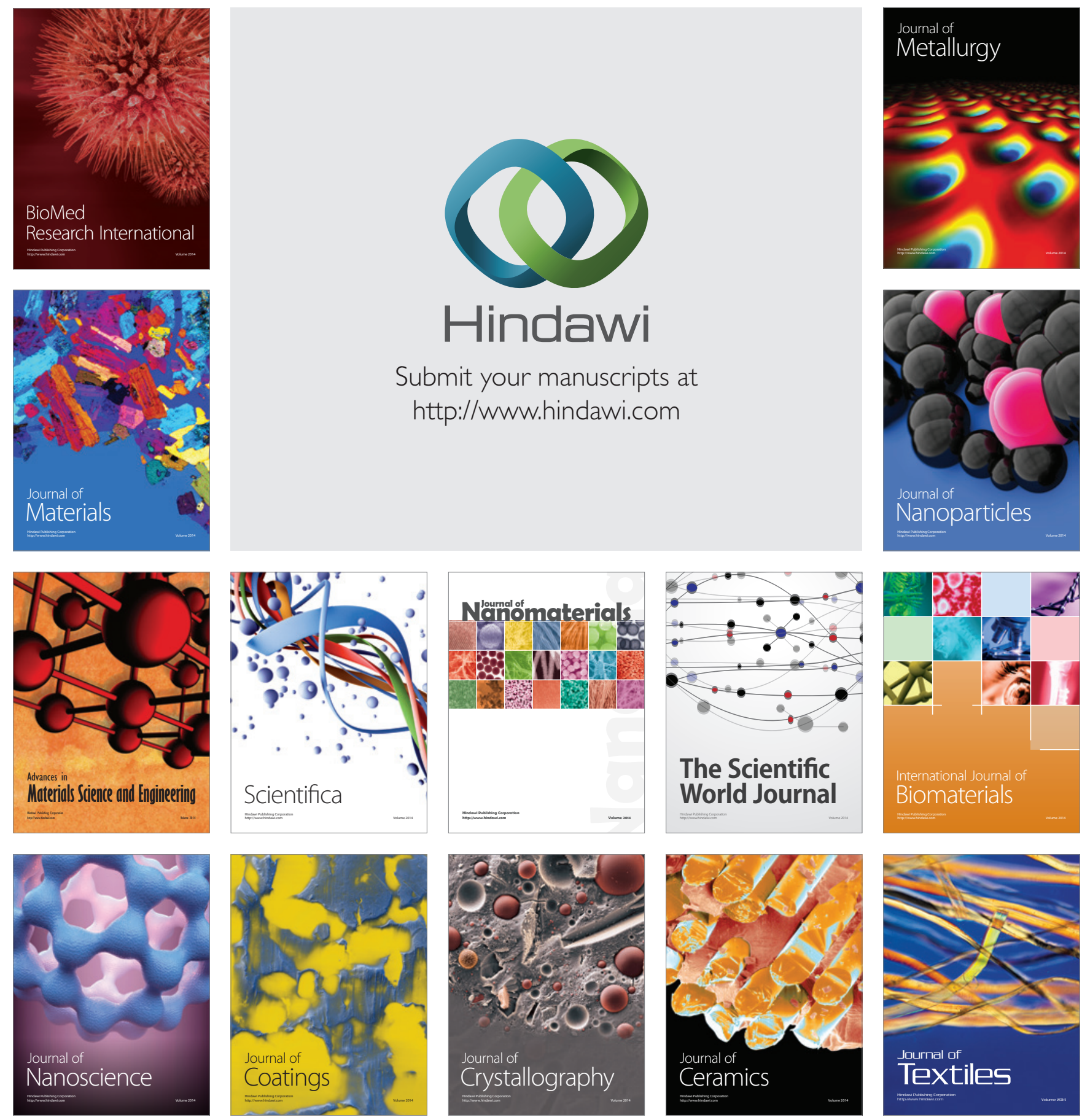